\title{
THE POSSIBLE INFLUENCE OF CURRICULUM STATEMENTS AND TEXTBOOKS ON MISCONCEPTIONS: THE CASE OF EVOLUTION
}

\section{Martie Sanders}

Animal, Plant and Environmental Sciences

University of the Witwatersrand

Email: Martie.Sanders@wits.ac.za

\section{Dennis Makotsa}

Animal, Plant and Environmental Sciences

University of the Witwatersrand

\section{ABSTRACT}

Curriculum statements and textbooks are considered to be vital support tools for teachers, particularly during times of curriculum innovation. A recent change in South Africa was the controversial inclusion of evolution in the school curriculum, raising serious concerns amongst biology teachers regarding the adequacy of their content and pedagogical content knowledge for teaching the topic. Widespread 'misconceptions' about evolution make teaching this topic difficult for biology teachers worldwide. Identifying the sources of errors is an essential step needed before addressing them. This study explored curriculum support materials as a possible source of misconceptions, using content analysis of the South African school Natural Sciences curriculum statement and six Grade 7-9 Natural Sciences textbooks from two different publishers, and investigated 'curriculum slippages' between the 'formal' and 'perceived' curricula. The aim was to determine the nature and extent of unscientific ideas about evolution, and

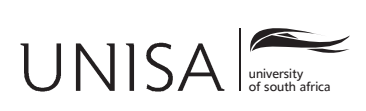

Education as Change www.educationaschange.co.za Volume 20 | Number 1 | 2016 pp. 216-238

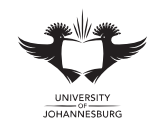

DOI: http://dx.doi.org/10.17159/1947-9417/2015/555 Print ISSN 1682-3206 | Online 1947-9417 (C) 2016 The Authors 
to see how authors dealt with potential misconceptions. Errors were found in the curriculum statement and in the textbooks, where they escalated in frequency. Latent problems associated with ambiguous wording of statements posed further problems. Although this paper uses evolution as an example, lessons learned about curriculum materials as a possible influence on misconceptions are applicable to other subjects.

Keywords: curriculum support materials, textbooks, misconceptions, curriculum slippages, evolution, natural selection

In times of curriculum innovation textbooks become important props for teachers, particularly if they are inadequately prepared to implement new curriculum content. However, an important assumption is that such support materials will be scientifically accurate. If they contain errors, teachers with poor content knowledge may not be in a position to recognise mistakes, which are thus likely to be transmitted to pupils. This paper focuses on an investigation of curriculum statements and textbooks as a possible source of misconceptions, as well as how the textbooks identified and addressed common misconceptions. We have used the umbrella term 'misconceptions' for this paper in the commonly understood everyday sense, referring to incorrect ideas, as this is how most teachers and the public are likely to understand the term. Because document analysis was used for this study it was not possible to discriminate between ideas which have been mentally constructed by the document authors (the correct technical meaning of 'misconceptions') and 'errors', which have been acquired from some outside source.

\section{THE CONTEXT OF THE STUDY}

\section{The inclusion of evolution in the South African school curriculum}

The radical revision of the South African school curriculum, progressively implemented by the newly elected government's education department between 1998 and 2008, was characterised by several changes, one of which was a modernising of the science curriculum in terms of content. The most dramatic change was the inclusion of evolution by natural selection. A widely held but somewhat inaccurate perception is that evolution was excluded from the school curriculum during the almost 50 years that the National Party governed the country (1948 to April 1994), because any knowledge considered at variance with the Christian National Education (CNE) policy, which underpinned previous school curricula, was omitted. However, tracking the history of evolution in South African schooling, Lever (2002:34) explains that CNE policy, which espoused the belief captured in a 1948 publication of CNE ideals that 'the spirit and direction of every subject taught must correspond to the Christian and National life- and world-view ... and that in no subject may antiChristian, unchristian or anti-national or un-national propaganda be conveyed', was 
only officially implemented in 1967. Furthermore, Darwin was included in a brief history of leading biological figures in a 1947 syllabus used for some years under the National Party rule, and Lever (2002:36) suggests that the syllabus functioning in the 1950s (inherited by the National Party when they came into power in 1948) was more a case of 'non-Darwinism than anti-Darwinism'. Furthermore, Dada (2002), investigating changes in biology textbooks, found mixed results in books she reviewed from the 1980s (Nationalist era) and 1990s (African National Congress era, but prior to any curriculum changes). Three of four books reviewed referred to evolution, although one mistakenly claimed there was no evidence that major evolutionary changes happened by natural selection, and that 'whichever view one takes is largely a matter of faith' (Dada 2002:128). It thus appears that political influences on the inclusion of evolution in the school curriculum during the last five decades of the twentieth century are not clear cut, and the inclusion of evolution possibly depended on, among other factors, publishers' policies and the textbooks selected by schools.

Evolution-related topics were formally introduced into the South African school curriculum at the General Education and Training (GET) level (Grades R to 9) when the Revised National Curriculum Statement (RNCS) was introduced from Grade R in 2004. However, the term 'evolution' was not used in the Natural Sciences learning area, probably to avoid potential controversy. Nevertheless, the essential elements of evolution were included: adaptations, extinctions, natural selection, and fossils. In the History section of the Social Sciences learning area, the term 'evolution' was used, with the topic of human evolution being included in Grade 7, dealing with early hominid discoveries in south and east Africa, and 'becoming human in southern Africa' (Department of Education 2004). Concerns about including evolution in school curricula only started to emerge when evolution made its appearance at the Further Education and Training level (Grades 10 to 12) in 2008, in the externally examinable Grade 12 Life Sciences curriculum. This inclusion meant teachers could not omit the topic as some GET teachers had been doing. The Life Sciences curriculum has since undergone two revisions, the first of which (starting in 2009) saw evolution-related content spreading down from Grade 12 into the Grade 10 and Grade 11 curricula. The second revision (referred to as CAPS, the Curriculum and Assessment Policy Statement) was implemented in Grades 10 to 12 from 2012 to 2014. The new CAPS curriculum was also implemented at the GET level, starting with Grades 4 to 6 in 2013, with final implementation in Grades 7 to 9 in 2014. Although natural selection has inexplicably been removed from the GET Natural Sciences curriculum, adaptations (which occur by natural selection) remain.

The inclusion of evolution-related concepts in the draft Revised National Curriculum Statement 'provoked a storm of controversy' from conservative religious groups, departmental officials, teacher unionists, and academics (Chisholm 2002:53). Twenty-one per cent of the concerns identified by teachers in one study related to a potential religion-evolution conflict for religious parents and pupils, as well as 
clashes with their own religious beliefs (Sanders and Ngxola 2009). However, not all religious groups were anti-evolution, and because learning about evolution was considered 'critical' (Chisholm 2002:51) the final RNCS retained the evolutionrelated topics.

\section{Reasons for including evolution in biology curricula}

From an educational point of view the omission of evolution from any curriculum dealing with biology is incomprehensible. The National Academy of Sciences(2008:ix) describes evolution as 'the cornerstone of modern sciences' and numerous scientists (for example, Futuyma 2009) consider the theory of evolution to be one of the most powerful ideas in the sciences. Firstly, evolution provides an explanatory framework for understanding many of the fundamental phenomena, principles and processes that explain the living world, many of which could not previously be explained. Lever (2002:40) thus describes evolution as 'the scaffolding of our current biological knowledge'. Indeed, an understanding of evolution is considered an important aspect of scientific literacy. Secondly, evolution is a unifying theme that links many disparate fields, both within biology (for example, genetics, anatomy, embryology and molecular biology) and in other sciences (such as geology, palaeontology and archaeology). These links allow for otherwise fragmented information to be collated to form a holistic overview or model of the living world (Nehm, Poole, Lyford, Hoskins, Carruth, Ewers and Colberg 2009). Thirdly, an understanding of the theory of evolution has resulted in many scientific and technological advances in areas such as medicine, agriculture and conservation (National Academy of Sciences 2008; Futuyma 2009), contributing to a better quality of life.

\section{PROBLEMS MOTIVATING THE STUDY}

Three problems motivated this study. The first is that the misconceptions about evolution prevalent among scholars internationally at all educational levels, both before officially being taught the topic and often afterwards (for example, Bishop and Anderson 1990; Moore et al. 2002) are also prevalent among South African pupils (Kagan and Sanders 2013; Lawrence 2015; Moore et al. 2002; Mpeta 2013; Schroder 2012; Yalvac 2011). Having misconceptions is, in itself, problematic, but a more serious consequence is that erroneous ideas interfere with the success of further learning (Freyberg and Osborne 1985) and tend to be difficult to teach away (Helldén and Solomon 2004). The existence of misconceptions has serious consequences when evolution is meant to provide an underlying framework for explaining basic processes and phenomena in the biological sciences.

The second problem motivating the study relates to questions about the preparedness of many South African teachers to teach evolution. There are four areas of concern: Firstly, teachers' inadequate content knowledge regarding evolution (Ngxola 
and Sanders 2009; Pillay 2011), probably because many of them had not received appropriate evolution-related education or training prior to the implementation of the new curriculum (Abrie 2010; Pillay 2011; Stears 2006) and because 'training for both Curriculum 2005 and the National Curriculum Statement was shown to be too superficial and too generic' and 'decontextualized and unsupported', resulting in poor implementation of policies (Department of Basic Education 2009:55-56). Secondly, in addition to teachers lacking content knowledge, several studies have found that many South African teachers (Molefe 2013; Naudé 2013; Ngxola and Sanders 2009; Pillay 2011; Yalvac 2011) and student-teachers (Abrie 2010; Stears 2012) have misconceptions about evolution. Thirdly, many teachers (Naudé 2013; Pillay 2011; Sanders 2010; Sanders and Ngxola 2009; Yalvac 2011) and student-teachers (Abrie 2010) have voiced attitude-related concerns (their own, parents', or learners') about a potential religion/evolution controversy, some expressing an unwillingness to teach evolution. These attitudes are often fuelled by the common misconception that believing in God and accepting evolution are mutually exclusive (Stears 2012). Fourthly, evolution has been recognised as an abstract and difficult concept to teach (Bishop and Anderson 1990), and the pedagogical content knowledge of many South African teachers for teaching the topic, particularly how to manage the emotional arguments arising from strongly held religious beliefs, appears inadequate (Molefe 2013). It is important to know, for example, that introducing argumentation to teach the topic of evolution generates conflict for many religious students, and that students' concerns can be avoided or reduced using 'independence' or 'dialogue' strategies (Anderson 2007) when teaching the topic. Teachers' lack of confidence about teaching evolution has been exacerbated by the constant curriculum changes at the FET level, where the third version of the Life Sciences curriculum statement within six years was fully implemented by December 2014. A review by the Department of Basic Education (2009:48) found that 'there was a strong call from teachers for guidance regarding how to realize the content: that more explicit direction regarding how to teach a particular subject is given'.

If teachers are inadequately prepared, the role of curriculum support materials becomes critical (Ball and Cohen 1996; Hutchinson and Torres 1994; Ottevanger 2001). The availability of textbooks has proved repeatedly to be the major factor predicting learning success in developing countries, defining the scope and structuring of the content to be taught, providing guidance on pedagogy, and saving time in providing a record of correct information for students (Verspoor and $\mathrm{Wu}$ 1990). However, an assumption underpinning their use is that the content provided will be scientifically accurate. The third problem motivating the study involves the questionable quality of curriculum support materials (including curriculum statements and textbooks) provided for South African teachers. The curriculum review expressed two concerns regarding the curriculum statements. Firstly, specifying GET Natural Sciences content by phase rather than by grade caused 
problems in textbooks, which are written for grades (Department of Basic Education 2009). Secondly, there are conceptual errors regarding evolution in the Revised National Curriculum Statement, as also pointed out by Dempster and Hugo (2006).

The review also emphasised the central role of textbooks to ensure content coverage, to help teachers with year and lesson planning, and to keep pace with the changing revisions to the curriculum statements. Two concerns were raised regarding textbooks: the need for constant production of new editions to keep up with the revisions to the curriculum documents (Department of Basic Education 2009) and the possibility that local textbooks contained errors. If, as seems likely because of their inadequate education and training about evolution, teachers are heavily reliant on textbooks, then having errors in the books is extremely problematic because mistakes are likely to be transmitted to pupils by any teachers unable to recognise errors. Having misconceptions themselves also means that teachers cannot act as filters for poor quality curriculum materials, a role Abimbola and Baba (1996) believe teachers should fulfil.

\section{THE AIM OF THE STUDY}

To address the problem of misconceptions it is first necessary to establish their source, so that the causes can be targeted. The aim of this study was to investigate Senior Phase (Grade 7 to 9) curriculum support materials (the curriculum statement and textbooks) for the Natural Sciences as a possible influence on unscientific ideas about evolution. Because of their role in supporting teachers, we went further than just investigating support materials as a potential source of misconceptions, and also looked at whether they supported teachers to identify and address misconceptions. As the CAPS revisions were not yet fully implemented, RNCS materials in use at the time of the study were investigated.

\section{THE CONCEPTUAL FRAMEWORK FOR THE STUDY}

Conceptual frameworks are important for improving the quality of research, helping researchers to design appropriate investigations and to interpret the data against a background of research-based and theoretical information usually derived from the relevant literature (Miles and Huberman 1994). The literature-based framework for this study comprised five main constructs (see Figure 1), which, although associated, could not easily be linked into a single coherent conceptual framework. Abd-ElKhalick and Akerson (2007) warn that the complexity of science education means that researchers will seldom find a single, ready-made existing conceptual framework to underpin their studies, and that frameworks often simply describe the constructs relevant to the research topic, and the relationships between them. 


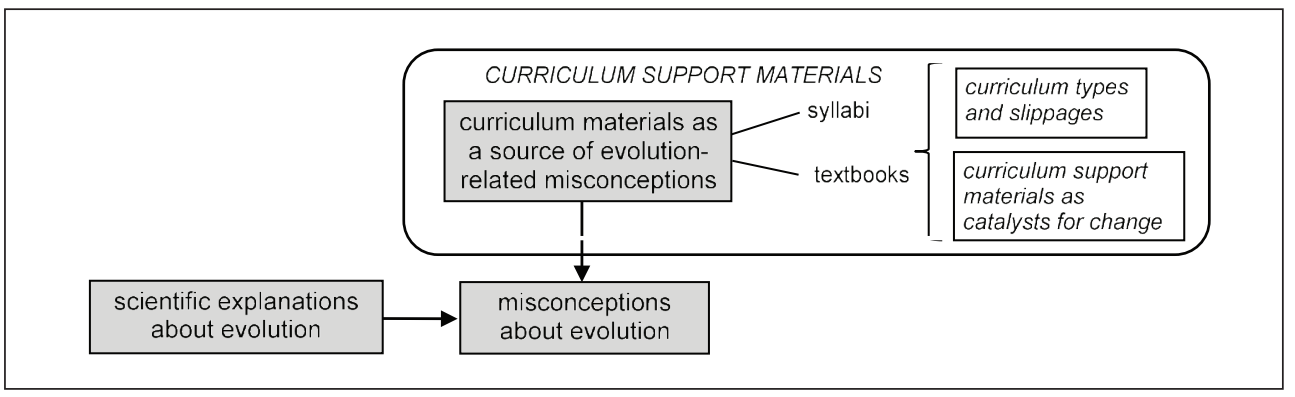

Figure 1: Conceptual framework for the study

Three research-based constructs (grey boxes in Figure 1) were considered. Firstly, a thorough review of the scientific explanations for evolution by natural selection was completed so that ideas in the curriculum materials not in line with scientific thinking could be recognised more easily. Futuyma (2009) provides a list of 16 points that summarise essential components of current evolutionary thinking (known as 'the evolutionary synthesis'). However, for a basic understanding of evolution by the process of natural selection, such as that required by members of the public or school-level pupils to understand evolution without misconceptions, the essence of the concept can be captured in just six points: 1) Individual organisms in a population (all individuals of a species living in a particular area) show physical and behavioural variations based on slight differences in their genetic make-up; 2) Some of the variations confer survival advantages to the individual in its particular niche; 3) Individuals with these traits will be reproductively more successful (more 'fit') than those without the traits; 4) Because of their reproductive success the favourable traits will be passed on to more offspring in the next generation than less favourable features; 5) The advantageous trait will therefore become more common in the population of organisms over time; and 6) After many generations the population will have changed notably, that is, will have evolved. Evolutionary changes in a population are often referred to as adaptations, but adaptations are no more than the consequences of evolutionary developments in populations over many generations, making the populations more suited to their environments.

Secondly, a review of common misconceptions about evolution was conducted to prime the researchers regarding what to look for. An extensive review of more than 50 papers shows that many of the misconceptions are common in countries across the world, and that they often persist across different educational levels. Many of the commonest misconceptions are encapsulated in the two alternative frameworks discussed later in the paper.

Thirdly, a broad review of sources of misconceptions was completed, eventually focusing on textbook problems specifically linked to evolution-related matters. This information formed the basis for the checklists developed to identify and capture the 
manifest and latent errors in the books analysed. Textbooks have been shown to be a source of errors in biology (Cho et al. 1985) including evolution-related ones (for example, Jiménez Aleixandre 1994; Rees 2007; Stern 2004), although no systematic analysis of such errors has been done. Several problems have been identified. First, separation of related content in textbooks is likely to cause fragmented thinking and inhibit the construction of mental models necessary for understanding topics such as evolution (Nehm et al. 2009). Furthermore, inappropriate sequencing of such 'fragments' can cause additional problems (Nehm et al. 2009; Cho et al. 1985), as discussed later. Second, the use of certain 'risk-terms' may cause problems. These include i) avoidance of the possibly contentious but necessary term 'evolution' (Nehm, Rector and Ha 2010; Woodward and Elliott 1987), by using euphemisms such as 'develop' and 'become' (Thompson 2008); ii) the problem of paradoxical jargon - words with different everyday and scientific meanings depending on their context of use, for example, 'the theory of evolution', 'adaptation', 'extinction', and the use of 'force talk' terms such as 'selection pressure' (Nehm et al. 2010); and iii) the inappropriate use of 'Darwinism' or 'Darwin's theory' to refer to evolution, when in fact the modern evolutionary synthesis has moved far beyond the original understanding of Darwin (Braterman and Holbrook 2009; Futuyma 2009).

Two theoretical constructs (italicised text in unshaded boxes in Figure 1) associated with curriculum materials assisted in interpreting the findings. The first was a useful theory for understanding curriculum documents - the notion that a curriculum undergoes transformations from the time of conceptualisation to the time it is experienced in the classroom (Goodlad, Klein and Tye 1979). These transformations make it very difficult to define 'the' curriculum because various types of curricula emerge during the development and implementation process of any curriculum, as shown in Figure 2. The original domains (types) of curriculum identified by Goodlad et al. (1979) have been modified and sometimes renamed by other authors (for example, Van den Akker 2004).

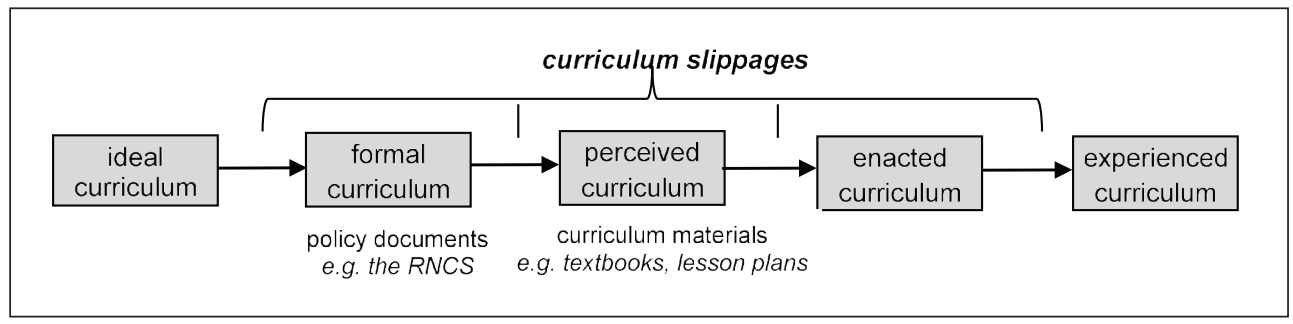

Figure 2: Summary of curriculum domains, and transformations and slippages occurring as a curriculum is implemented

The ideal curriculum is the initial curriculum envisaged by the planners and designers, often ideologically motivated, and not necessarily captured on paper. 
Once documented, modified and approved by the education authorities a slightly transformed written version, constrained by the realities of the education system, it becomes the formal curriculum (policy documents such as syllabi and curriculum statements). These are dispersed to relevant stakeholders such as textbook publishers and teachers, who interpret the curriculum documents in their own unique ways, resulting in the perceived curriculum (or, indeed, curricula). These are used by publishers and teachers to produce curriculum materials and to plan lessons. Once these materials are used in the classroom, the enacted curriculum comes into effect, which in turn is transformed into the experienced curriculum based on what students perceive has happened in the lessons. Goodlad et al. (1979) point out that the diffusion of any curriculum is characterised by distortions, which they refer to as 'slippages' that arise during the implementation process. The formal curriculum (policy document) is rarely transmitted in its entirety to the perceived curriculum reflected in curriculum materials produced by publishers and teachers. Chisholm (2002:53) explains that curriculum policy documents do not provide details, and '[t]he curriculum must be fleshed out by textbooks and teachers'. What teachers do in the enacted curriculum is influenced by the curriculum support materials. Should there be errors in the policy documents and textbooks they are likely to be passed on to pupils, thereby compromising the quality of teaching and learning.

Curriculum materials can serve to support teachers by improving their content knowledge and methods of teaching (Ball and Cohen 1996). Hutchinson and Torres (1994) argue that curriculum changes increase time and energy demands on teachers, and that having suitable textbooks reduces such demands. The second theoretical construct used in the conceptual framework is the 'teacher support materials as catalyst' model for curriculum implementation (Ottevanger 2001). This model uses the analogy of an enzyme-catalysed chemical reaction to explain how curriculum support materials (such as textbooks) can facilitate the implementation of science curriculum reforms. Enzymes can act as catalysts during chemical reactions, lowering the activation energy and time required for the reaction to get going. In a similar way, appropriate curriculum support materials can catalyse the implementation of the curriculum change, reducing the amount of time and energy teachers must invest to bring about change in the classroom.

\section{RESEARCH METHODS}

Content analysis, 'a research method that uses a set of procedures to make valid inferences from text' (Weber 1990:9), was used to research the documents for this study. The procedures outlined by Krippendorf (2013) were followed: selecting a sample; identifying the unit of analysis; developing the coding categories before starting the analysis; coding; inter-coder reliability checking. The documents analysed were the Revised National Curriculum Statement Natural Sciences (Department of Education 2002) in use at the time of the study and six Senior Phase (Grade 7-9) 
Natural Sciences textbooks from two publishers arbitrarily sampled from complete sets of textbooks donated for this research by five of the eight different South African publishers. A 'complete set' comprised a book for each of the Senior Phase grades $(7,8$, and 9). Prerequisite knowledge necessary for understanding evolution but not directly evolution-based (for example, genetics, biodiversity, and classification) was excluded. The relevant chapters from the textbooks (that is, adaptations, fossils, natural selection, biogeography, phylogenetic trees, and evolutionary trends) were identified and photocopied so that mark-ups did not damage the actual books. Initial analysis of the Grade 7 textbook from Publisher A showed it did not deal with evolution-related content, so it was not analysed further.

All relevant information that could either positively or negatively influence erroneous ideas about evolution was then 'marked up' using a highlighter pen. The unit of analysis varied from words, to phrases, to whole sentences - each unit chosen on the basis of being a self-contained, coherent segment of information. Information marked included manifest errors (described by Fraenkel, Wallen, and Hyun (2012) as obvious and easily detectable mistakes not requiring inferences to be made) and latent problems (inferences requiring some interpretation of the text, thus having the potential to be misinterpreted so that misconceptions could form). Fragmentation and sequencing problems were signposted because they have the potential to inhibit the development of a coherent understanding of evolution (Nehm et al. 2009). In addition, positive factors such as misconceptions being identified and/or addressed, or links being made between fragmented sections, were also highlighted. Once the second author had done this, the first author, using a different colour highlighter, checked the mark-up, to delete inappropriate segments, confirm what had been appropriately marked, and add any missing segments. The few small discrepancies were discussed until both researchers reached agreement that all appropriate content (and only appropriate content) had been 'marked-up'.

The marked-up 'units' were then coded. Coding is often interpreted as allocation of abbreviated codes during the analysis process, but developing a coding system is more about developing a classification system for categories identified in the data. The coding system developed for the study used both deductive and inductive methods, starting with factors identified in the literature as having an impact on misconceptions (as discussed in the conceptual framework), but adding new factors and categories as they emerged during the analysis. As pointed out by Miles and Huberman (1994), developing the coding system is an iterative and on-going process because new categories keep emerging as more sections are analysed. Abbreviated codes were used as convenient shorthand to identify factors on the document copies, but are not used to report the results.

Gawande (2011) suggests that checklists can improve consistency (reliability). Two open-ended electronic checklists were developed to 'capture' and code the data, serving to reduce the data, and to improve reliability. Actual quotes from the documents were electronically captured and coded to serve as the basis for later 
frequency counts, and as a source of evidence. The first checklist included columns for i) manifest errors; ii) latent problems; and iii) positive factors (such as identification of misconceptions, explanations of the correct science, or links between fragmented sections). The second checklist focused on fragmentation and sequencing issues. Inter-coder reliability was conducted by the two authors independently coding the chapters, and then meeting to make comparisons and discuss where discrepancies arose, ultimately reaching consensus on the data captured and the codes allocated. The few minor disagreements were settled after consultation with two senior university academics who teach evolution courses.

\section{FINDINGS AND DISCUSSION}

\section{Fragmentation and sequencing problems}

The 'ideal curriculum' for the teaching of evolution by natural selection across school grade levels is epitomised, for example, in the three relevant grade-related concept maps of the American Association for the Advancement of Science (2001). However, the reality of the demands of education systems places constraints on what can be taught in the time available, with existing resources, and within the structural framework of grade levels and topic areas, so the resulting 'formal curriculum' is often somewhat different. Competing interests of those drawing up the curriculum also impact on the resulting 'formal' curriculum. Table 1 summarises the evolutionrelated topics in the 'formal curriculum' in use at the time of the study, the RNCS Natural Sciences (Department of Education 2002). The document itself was fragmented, being divided into four content strands (the two with evolution-related content, shown in Table 1, being Life and Living, and Planet Earth and Beyond), each divided into three sub-strands (see Table 1 for the two evolution-related ones for each strand), guided by a 'unifying statement'. The RNCS used grade-associated 'phases' to specify approximately when content is to be taught. 
Table 1: Summary of evolution-related content in the RNCS Natural Sciences (Department of Education, 2002)

\begin{tabular}{|c|c|}
\hline \multicolumn{2}{|c|}{ Core knowledge and concepts in the Life and Living strand } \\
\hline \multirow[t]{2}{*}{$\begin{array}{l}\text { Interactions in } \\
\text { Environments }\end{array}$} & Biodiversity, Change and Continuity \\
\hline & $\begin{array}{l}\text { Unifying statement: The huge diversity of forms of life can be } \\
\text { understood in terms of a history of change in environments and } \\
\text { in characteristics of plants and animals throughout the world } \\
\text { over millions of years (p. } 62 \text { ) }\end{array}$ \\
\hline \multicolumn{2}{|c|}{ INTERMEDIATE PHASE (Grades 4 - 6) } \\
\hline & $\begin{array}{l}\text { - Offspring look like parents, but show slight differences } \\
\text { ('variation') (p. 63) } \\
\text { - The SA fossil record stretches over millions of years. Some } \\
\text { are similar to present day organisms, others very different. } \\
\text { (Links with fossils in Planet Earth and Beyond) (p. 63) }\end{array}$ \\
\hline \multicolumn{2}{|c|}{ SENIOR PHASE (Grades 7 - 9) } \\
\hline $\begin{array}{l}\text { - Characteristic } \\
\text { behaviours in species } \\
\text { arose over long } \\
\text { periods (p. 64) } \\
\text { - Organisms have } \\
\text { adaptations to } \\
\text { survive in their } \\
\text { habitat (p. 64) }\end{array}$ & $\begin{array}{l}\text { - Variation occurs in species (p. 64) } \\
\text { - Variations such as height and skin colour in humans do not } \\
\text { indicate innate abilities of groups (p. 64) } \\
\text { - Natural selection kills individuals of a species lacking the } \\
\text { characteristics which would have enabled them to survive and } \\
\text { reproduce successfully. Individuals with suitable } \\
\text { characteristics reproduce successfully. (p. 64) } \\
\text { Mass extinctions have occurred in the past (Links with Planet } \\
\text { Earth and Beyond) (p. 65) }\end{array}$ \\
\hline \multicolumn{2}{|c|}{ Core knowledge and concepts in the Planet Earth and Beyond strand } \\
\hline \multirow[t]{2}{*}{$\begin{array}{l}\text { Atmosphere and } \\
\text { Weather }\end{array}$} & The Changing Earth \\
\hline & $\begin{array}{l}\text { Unifying statement: The earth is composed of materials which } \\
\text { are continually being changed by forces on and under the } \\
\text { surface (p. 69) }\end{array}$ \\
\hline \multicolumn{2}{|l|}{ INTERMEDIATE PHASE } \\
\hline & $\begin{array}{l}\text { - Land forms change (can be very slow or fast). Formation of } \\
\text { sedimentary rock. (p.69) } \\
\text { - Fossils (remains of past life forms preserved in stone) show } \\
\text { life in the past was different (Links with Life and Living) (p. 70) }\end{array}$ \\
\hline
\end{tabular}




\begin{tabular}{|l|l|}
\hline \multicolumn{2}{|l|}{ SENIOR PHASE } \\
\hline $\begin{array}{l}\text { - Plants and animals } \\
\text { are adapted to }\end{array}$ & $\begin{array}{l}\text { - Large plates move very slowly. Deposition of sediments. } \\
\text { (p. 71) }\end{array}$ \\
$\begin{array}{l}\bullet \text { Many SA fossils differ from current organisms, and occur in } \\
\text { (Links with Life \& }\end{array}$ & $\begin{array}{l}\text { areas where today's conditions would not suit them. This } \\
\text { Living) (p. 71) }\end{array}$ \\
& shows life and conditions on Earth have changed over time. \\
& (Links with Life and Living) (p. 72) \\
\hline
\end{tabular}

Underlined statements are scientifically incorrect (misconceptions)

The fragmentation of evolution-related topics between two knowledge strands, four sub-strands (and two of the associated unifying statements), and two phases spanning grades 4 to 9 , is clearly visible in Table 1 , which also shows the element of repetition. For example, the content on fossils was addressed in different phases and strands, perhaps with a 'spiral curriculum' in mind. Furthermore, not shown in Table 1 is that evolution-related topics on hominids appeared in the History strand of the Social Sciences curriculum statement. Whatever the reasons for this fragmentation, the likely consequence is the warning offered by Nehm et al. (2009) that the formation of a coherent mental model about evolutionary change is likely to be made extremely difficult. On the positive side, efforts were made to provide cross-referencing links between various sections of the curriculum statement (see italicised text in Table 1).

Analysis of the textbooks also revealed both fragmentation of evolution-related content, and sequencing problems, mirroring the RNCS layout. Discussions with publishers and textbook authors at workshops we ran to share our findings revealed that if publishers do not follow the layout and sequencing of the RNCS, their textbooks are not selected for the list of approved books. Grey (1999:4) claims 'without the official stamp of approval the textbook is as good as "banned". Publication pressures are also noted elsewhere in the world (Woodward and Elliott 1987). Fragmentation in the textbooks followed the fragmentation of the RNCS, with evolution-related content appearing in different chapters and grades. Nehm et al. (2009) point out that such fragmentation will not only inhibit holistic thinking about evolution, but that isolating such topics into specific 'evolution' chapters (as was found in our study) makes it very difficult for students to see evolution as a unifying theme that underpins all topics in biology. In terms of sequencing, pre-requisite knowledge essential for understanding a topic should be taught first. For example, natural selection should be taught before looking at the process of adaptation, which occurs by means of natural selection. Although the Natural Sciences RNCS did not spell out in which specific grade (in a phase) content should be taught, Publisher A addressed content on adaptations at Grade 8 level, and only included variation and natural selection (necessary to understand adaptation) later, in Grade 9. Cho et al. (1985) argue that both fragmentation of relevant aspects of a topic, and poor sequencing, are likely to result in misconceptions. 


\section{Manifest errors}

Scientifically incorrect statements were found in every document analysed. Table 2 summarises the most frequently occurring errors, all of which are identified in studies of student's misconceptions worldwide. Two common unscientific 'alternative frameworks' (incorrect underlying beliefs that lead to a cluster of associated errors) dominate the list. The first is the 'evolution on demand' notion of adaptation (Tshuma and Sanders 2015). This seems to be driven by anthropomorphic and teleological thinking (the first endowing organisms with a human-like ability to reason and take action to avoid potential future negative consequences, and the second explaining phenomena by the function they serve, rather than their actual scientific cause). Four misconceptions associated with the 'evolution on demand' alternative framework were identified in the textbooks, although they did not occur in the RNCS: that adaptation is i) caused by changing environments and food sources $(n=3)$, ii) that individuals evolve $(\mathrm{n}=9)$, iii) by purposely initiating and controlling the change $(\mathrm{n}=5)$, iv) in order to survive ( $\mathrm{n}=5$ ). Scientists (for example, Futuyma 2009) explain that natural selection is the process causing adaptations, increasing the frequency in a population (over many generations) of favourable alleles already present in individuals in the population. Changing conditions are not necessary for and do not initiate natural selection, but may provide circumstances that facilitate selection of pre-existing phenotypes (as correctly explained in the RNCS, see Table 1). Furthermore, individuals cannot foresee their possible future, or control and change their genotype, and hence phenotype (Gregory 2009). While GET-level pupils will not yet have dealt with genetics, the concepts here are well within their reach if teachers and textbooks refer simply to what they look like (rather than phenotypes) and how this is controlled by their genes (a notion familiar to most pupils of this age as a concept commonly encountered in the public domain).

The second alternative framework is associated with the misleading metaphor, 'survival of the fittest'. This leads to the unscientific notions that only the fittest a) survive $(\mathrm{n}=10)$, and $\mathrm{b})$ reproduce $(\mathrm{n}=4)$, and that $\mathrm{c})$ the 'less fit' do neither $(\mathrm{n}=5)$; and d) that favourable traits will be inherited by the offspring $(\mathrm{n}=6)$, until e) all individuals in the population eventually have the favourable trait $(n=2)$. In fact even 'fit' organisms may die (from disease, predation etc.) and many less well-endowed individuals nevertheless survive and reproduce. Inheritance of alleles by all offspring depends on dominance and/or on homozygosity of the alleles, so specific traits are not always inherited by all offspring. Furthermore, less favourable alleles may remain in the population, although in reduced proportions. Other misconceptions were found, for example, the overgeneralised and hence incorrect claim that fossils are preserved in stone, thus ignoring fossils found in ice and amber, for example. 
Table 2: Summary of RNCS and most frequent textbook misconceptions

\begin{tabular}{|l|c|c|c|c|}
\hline & RNCS & \multicolumn{2}{|l|}{ Publisher } & Textbook \\
\cline { 3 - 6 } & & A & B & totals \\
\hline $\begin{array}{l}\text { Percentage of pages of the book series dealing with } \\
\text { evolution-related matters }\end{array}$ & & 6.0 & 6.3 & \\
\hline Total number of different misconceptions & 3 & 12 & 16 & $19^{*}$ \\
\hline Total number of occurrences & 4 & 41 & 22 & 63 \\
\hline $\begin{array}{l}\text { Evolution is caused by changing environments or food } \\
\text { sources (i) }\end{array}$ & & 2 & 1 & 3 \\
\hline Individual organisms evolve (ii) & & 8 & 1 & 9 \\
\hline Evolution involves organisms changing themselves (iii) & & 5 & 0 & 5 \\
\hline $\begin{array}{l}\text { Organisms change because they need to (in order to } \\
\text { survive) (iv) }\end{array}$ & & 5 & 0 & 5 \\
\hline Individuals with favourable characteristics will survive (a) & & 6 & 4 & 10 \\
\hline $\begin{array}{l}\text { Individuals with favourable characteristics will reproduce / } \\
\text { others won't (b/c) }\end{array}$ & 2 & 3 & 1 & 4 \\
\hline The less 'fit' die (c) & 1 & 2 & 3 & 5 \\
\hline $\begin{array}{l}\text { Favourable characteristics will be inherited by the } \\
\text { offspring (d) }\end{array}$ & & 4 & 2 & 6 \\
\hline $\begin{array}{l}\text { Eventually all organisms in a population will have the } \\
\text { favourable traits (e) }\end{array}$ & & 2 & 0 & 2 \\
\hline Fossils are preserved in stone & 2 & 2 & 8 & 10 \\
\hline Other misconceptions (less frequent) & & 2 & 4 \\
\hline
\end{tabular}

*The misconceptions for each publisher were not necessarily different ones, so this is not the sum of $A$ and $B$

Each misconception identified in the RNCS $(n=3)$ escalated in frequency of occurrence in the textbooks. The RNCS statement (p. 64, errors italicised by us), 'Natural selection kills those individuals of a species which lack the characteristics that would have enabled them to survive and reproduce successfully in their environment. Individuals which have characteristics suited to the environment reproduce successfully and some of their offspring carry the characteristics' translated into 19 errors in the textbooks. Interestingly, curriculum slippage is evident as the first of the two major alternative frameworks is not found in the RNCS document (representing the 'formal' curriculum), yet associated errors occur 22 times in the textbooks (representing the 'perceived' curriculum). Sometimes correct statements in the RNCS, for example, the correct RNCS statements "natural selection is accelerated when the environment changes' (not caused by) and 'some of their offspring carry the characteristics' (not all inherit) translate into errors in the textbooks (errors found 3 and 6 times, respectively). 
A comparison of books from the two different publishers shows that Publisher B had only about half the frequency of misconceptions that A had. If reasons for this could be ascertained, it might suggest what steps could be taken to reduce the problem. Is it more knowledgeable authors? More effective editorial checking? Greater determination not to perpetuate errors identified in policy documents? Furthermore, if authors identified and addressed in their textbooks commonly occurring misconceptions, misconceptions commonly held by both teachers and pupils might be reduced, although true misconceptions are difficult to eradicate. The books of Publisher B point out and correct 14 common misconceptions, for example 'People said there are no fossil links between major groups of animals. But in fact there are. We have fossils in the Karoo that are halfway between two big groups ... mammal-like reptiles' (B:Gr7:29). This book also has an excellent section that uses a historical approach to tactfully address misconceptions commonly used by creationists to refute evolution, and focuses on whether there are any valid scientific objections. They systematically identify common misconceptions (note, not religious beliefs regarding a six-day creation story), for example, they talk about the common 'idea that evolution is ungodly - but it is not. Evolution contradicts the idea that species were made from dust. But it does not deny God' (B:Gr7:29). After looking at several misconceptions they ask, 'What is the only remaining objection to evolution? Scientific or religious? .... Which Christian denominations do you know that accept evolution (there are many)' (B:Gr7:29).

\section{Latent errors}

Many of the statements identified in the textbooks, while not scientifically incorrect, involved the problematic use of language in ways which implied or could lead to misconceptions, that is, what Fraenkel et al. (2012) call 'latent errors'. The commonest latent errors found are summarised in Table 3.

Three types of 'inadequate explanations' emerged. Poorly worded explanations were the most common problem $(\mathrm{n}=40)$. They are statements where the meaning is unclear, sometimes because of poor language usage. For example, "desert animals have to use other ways of cooling because they cannot afford to lose water in this way" (A:Gr8:82). The anthropomorphic and teleological wording (Sanders 2014) of this explanation could cause misconceptions i, ii and iii, and even iv (see Table 2). Incomplete explanations $(\mathrm{n}=16)$ were the next most frequent. They lack essential information needed for full understanding of the concept being explained, for example, "evolution is change in a population of plants or animals over time" (B:Gr7:29), without further elaboration. The 'change' referred to needs clarification regarding existing traits becoming more frequent (and how) if evolution by natural selection is to be understood without any misconceptions forming. Furthermore, the relative phrase 'over time' is too vague, as to fully understand evolution it needs to be clarified that evolution takes many generations to happen, and the reasons for 
this need to be explained. Statements involving misleading wording $(\mathrm{n}=12)$ actually imply incorrect ideas likely to lead to misconceptions. For example, "describe how the gemsbok has adapted to survive desert conditions" (A:Gr8:83) sounds innocuous but overtly implies that individual organisms can adapt, do so purposefully, and that this is done in order to survive, inferring misconceptions ii, iii, and iv, respectively.

Table 3: Frequency of the commonest latent errors, by publisher and grade

\begin{tabular}{|c|c|c|c|c|c|c|c|}
\hline \multirow{3}{*}{\multicolumn{2}{|c|}{ Problem category }} & \multirow{2}{*}{\multicolumn{2}{|c|}{$\begin{array}{c}\text { Publisher A } \\
\text { Grade }\end{array}$}} & \multirow{2}{*}{\multicolumn{3}{|c|}{$\begin{array}{c}\text { Publisher B } \\
\text { Grade }\end{array}$}} & \multirow{4}{*}{$\begin{array}{c}\text { Totals } \\
40 \\
\end{array}$} \\
\hline & & & & & & & \\
\hline & & \multirow{2}{*}{$\begin{array}{l}8 \\
9\end{array}$} & \multirow{2}{*}{$\begin{array}{l}9 \\
9\end{array}$} & \multirow{2}{*}{$\begin{array}{l}7 \\
4 \\
\end{array}$} & \multirow{2}{*}{$\begin{array}{c}8 \\
11\end{array}$} & \multirow{2}{*}{$\begin{array}{l}9 \\
7\end{array}$} & \\
\hline Inadequate & Poorly explained & & & & & & \\
\hline explanations & Explanation incomplete & 3 & 3 & 8 & 1 & 1 & 16 \\
\hline & Misleading wording & 2 & 3 & 0 & 7 & 0 & 12 \\
\hline \multicolumn{2}{|c|}{$\begin{array}{l}\text { Problematic use of the risk-term } \\
\text { 'adapt(ation)' }\end{array}$} & 61 & 13 & 3 & 42 & 5 & 124 \\
\hline \multicolumn{2}{|c|}{$\begin{array}{l}\text { Problematic use of 'species' or } \\
\text { 'organisms' evolving }\end{array}$} & $1 / 0$ & $5 / 1$ & $0 / 1$ & $4 / 1$ & $0 / 0$ & $10 / 3$ \\
\hline
\end{tabular}

In addition to inadequately worded statements, the inappropriate use of 'risk-terms' in the textbooks was problematic. Such terms are latent errors because although the terms themselves are not incorrect, inappropriately used they imply errors. The two problems (inadequate explanations, and the use of risk terms) were often interwoven. Table 3 summarises the frequencies for three risk-terms, the most serious problem being with the term 'adapt' or 'adaptation', which was inappropriately used 124 times, often implying individual organisms acted anthropomorphically, trying to adapt to changing environments or food sources in an effort to survive. For example, a definition of 'adapt' in one book uses the everyday meaning of the word, rather than the scientific meaning: "Adapt - To adjust to a set of conditions" (B:Gr8:51). The everyday meaning has anthropomorphic and teleological connotations, and is likely to lead to misconceptions ii and iii. The scientific meaning of 'adapt' emphasises that only populations not individuals adapt, that they do so by natural selection, and that this takes many successive generations to happen. Bardupukar (2008) uses the term 'evolutionary adaptations', which we believe would help people make the link between adaptations and evolution, which might reduce the numerous misconceptions associated with the term 'adapt'.

There were numerous problematic instances regarding the use of the risk-terms 'organisms' and 'species' when referring to evolution. Talking about organisms evolving $(\mathrm{n}=10)$ greatly increases the chances of causing the misconception that individuals adapt and evolve, for example 'adaptations of different organisms' (B:Gr8:74) rather than populations of organisms. Similarly, careless use of 'species' 
evolving, when discussing a specific example $(n=3)$ can lead to the misconception that whole species evolve, when in fact only populations in an area evolve, not the whole species worldwide. 'Many species may not have been able to adapt to the change in climate' (A:Gr9:111). However, a new species can evolve in a particular area, and later spread.

Other risk-terms were found, but less frequently: for example, the misleading term 'Cradle of Humankind' is easily misinterpreted if not explained. The name implies that humans/human ancestors first evolved there, which is not true. This problem was identified in only one book, where the potential risk was escalated into a manifest error by actually stating (not just implying) that the oldest human remains were found there. It also erroneously equated the Cradle with Sterkfontein Caves only, and not the whole surrounding area plus two other geographically distant sites. "The Sterkfontein Caves in Gauteng are called the Cradle of Humankind because the oldest human remains have been excavated here" (B:Gr9:39). Care needs to be taken that when potential risk-terms are used, they are not used in ways that promote misconceptions identified earlier in the paper.

\section{CONCLUDING REMARKS}

Our review of more than 50 empirical studies involving pupils, university students and teachers, shows that most misconceptions reported about evolution and natural selection occur in many countries across the world, and are held by a large number of students at secondary and tertiary level, and even by teachers. Few studies, however, have analysed textbooks as a potential source of such errors. It is interesting to note which of these common misconceptions were found in the textbooks, and which were absent. Some of the frequent misconceptions found in the literature may be absent in the textbooks because they are about evolution, and not about the mechanisms behind it, and because they are so obviously scientifically incorrect. For example, the unscientific notion that evolution says that humans evolved from monkeys or apes, identified in almost half of the studies reviewed, was held by more than a fifth of each sample in studies with samples of over 400 (BouJahoude et al. 2011 in Egypt and Lebanon, where 37\% held this idea; Prinou et al. 2008 in Greece; and Yates and Marek 2014 in the USA). Yet this misconception did not appear in any of the textbooks we reviewed. Nor did the scientifically incorrect idea promulgated in the entertainment media that humans once hunted dinosaurs, which were long extinct when humans evolved. This was found in $21 \%, 35 \%$ and $13 \%$ of the samples in the three studies above. The errors we found in the textbooks were predominantly about the mechanism of evolution (natural selection) and almost all were associated with the two alternative frameworks 'evolution on demand' and 'survival of the fittest'. For example, the incorrect idea that individual organisms evolve was found in about a fifth of the studies reviewed, held by varying percentages of the samples. In two of the large studies it was held by $47 \%$ of the pupils (Prinou et al. 2008) and $77 \%$ of 
the post-tuition sample (Yates and Marek 2014). People holding this misconception often also believe that the organisms change because they need to (for example, $60 \%$ in the Prinou et al. study and 36\% in the Yates and Marek study), in order to survive changing environmental conditions (59\% in the Prinou et al. study). Prinou et al. (2008) found a statistically significant correlation between the misconceptions that organisms adapt because they need to survive, and organisms adapting to their environments. The inference is that if one holds an alternative framework (a broad way of thinking about a topic), many of the individual misconceptions associated with that framework will also be present.

This study contributes to the literature because it systematically and comprehensively analyses a potential source of unscientific ideas about evolution textbooks. It has also shown that many of these errors originate from scientifically incorrect statements in the official curriculum statement. Furthermore, the study has identified that latent errors (which are not errors per se, but are worded in such a way that they could cause errors) are a serious threat. We consider latent errors to be particularly problematic, because they are more frequent, and often appear to be correct yet are very likely to lead to misconceptions. Further research into how teachers and pupils actually interpret statements containing latent errors is needed to establish the extent of this potential threat. The occurrence of both manifest and latent errors in policy documents and textbooks diminishes their value as support documents for teachers whose content knowledge is weak.

The paper also revisits the idea of slippages between types of curricula. Textbooks are artefacts that contain a version of the perceived curriculum (as perceived by the textbook authors). Although errors were found in the textbooks even when not present in the curriculum statement (a good example of curriculum slippage), when there were errors in the curriculum statement they escalated in frequency in the textbooks. This poses serious problems for the teaching and learning of evolution when, as in South Africa, authors have to follow the curriculum statements or the textbooks do not appear on the 'approved list' from which government schools are supplied with their books. As pupils use the textbooks (as part of the enacted curriculum) any errors in the books are likely to be passed on to them. Furthermore, a gap in the support materials exists if misconceptions about evolution (identified in the research literature as a universal problem) are not actively dealt with by identifying (for teachers and pupils) common misconceptions and helping to correct them. Textbooks from Publisher B overtly pointed out misconceptions and offered explanations about why such claims were incorrect. The greater awareness of common misconceptions in the textbooks from Publisher B may also explain the much lower occurrence of misconceptions in the textbooks of these publishers.

It is important to note that document analysis cannot determine why erroneous statements occurred, for example, whether the textbook authors themselves supported such ideas or whether other pressures such as errors in the curriculum statements or in matriculation examination papers and memos (Reddy and Sanders 
2014) influenced the claims made in the books. Nor can document analysis determine whether unscientific statements are true misconceptions (mentally constructed ideas) held by authors or just errors acquired from other sources. Further research would be needed to establish this, and is important in trying to find solutions to the problem of errors in textbooks.

Although the study was limited to South African curriculum materials it seems likely that similar problems could occur elsewhere, which suggests avenues for further research. The value of this study is in providing evidence and raising awareness of the problems of actual errors and latent errors in curriculum support materials. While this information is important for teachers, it is critical for developers of instructional support materials, who would need to take action to correct problems in the policy statements and to avoid the problems in future textbooks. Immense care needs to be taken when wording explanations, as it is so easy to inadvertently make the types of latent errors identified in this study. Our workshops with publishers and authors, as well as subject advisors and teachers, have served to publicise the problem among stakeholders, who have been deeply concerned about the findings. Many are already taking appropriate action to deal with the problem.

\section{REFERENCES}

Abd-El-Khalick, F. and V. Akerson. 2007. On the role and use of "theory" in science education research: A response to Johnson, Sutherland and Sowell. Science Education 91(1):187-194.

Abimbola, I. and S. Baba. 1996. Misconceptions and alternative conceptions in science textbooks: The role of teachers as filters. The American Biology Teacher 58(1):14-19.

Abrie, A. 2010. Student teachers' attitudes towards and willingness to teach evolution in a changing South African environment. Journal of Biological Education 44(3):102-107.

American Association for the Advancement of Science. 2001. Atlas of science literacy. Washington, DC: American Association for the Advancement of Science.

Anderson, R. 2007. Teaching the theory of evolution in social, intellectual, and pedagogical context, Science Education 91(4):664-677.

Ball, D. and D. Cohen. 1996. Reform by the book: what is - or might be - the role of curriculum materials in teacher learning and instructional reforms? Educational Researcher 25(9):6-14.

Bardupukar, A. 2008. Do students see the 'selection' in organic evolution? A critical review of the causal structure of student explanations. Evolution: Education and Outreach 1(3):299-305.

BouJaoude, S., J. Wiles, A. Asghar and B. Alters. 2011. Muslim Egyptian and Lebanese students' conceptions of biological evolution. Science \& Education 20(9):895-915.

Bishop, B. and C. Anderson. 1990. Students conceptions of natural selection and its role in evolution. Journal of Research in Science Teaching 27(5):415-427.

Braterman, P. and J. Holbrook. 2009. Putting Darwin in his place: The need to watch our language. The American Biology Teacher 71(2):84-88.

Chisholm, L. (2002). Religion, science and evolution in South Africa: The politics and construction of the Revised National Curriculum Statement for Schools (R-9). In James, W. and Wilson, 
L. (Eds.), The architect and the scaffold: Evolution and education in South Africa, 51-59. Cape Town: Human Sciences Research Council.

Cho, H., J. Kahle and F. Nordland. 1985. An investigation of high school biology textbooks as sources of misconceptions and difficulties in genetics and some suggestions in teaching genetics. Science Education 69(5):707-719.

Dada, F. 2002. Science, evolution and book publishing: A publisher's dilemma. In James, W. and Wilson, L. (Eds.), The architect and the scaffold: Evolution and education in South Africa, 121-130. Cape Town: Human Sciences Research Council.

Dempster, E. and W. Hugo. 2006. Introducing the concept of evolution into South African schools. South African Journal of Science 102:106-112.

Department of Basic Education. 2009. Report of the task team for the review of the implementation of the National Curriculum Statement. Final report presented to the Minster of Education, October 2009.

Department of Education. 2002. Revised National Curriculum Statement for Grades R-9 (schools). Natural Sciences. Government Gazette No. 23406, Vol. 443. Pretoria: Department of Education.

Department of Education. 2004. C2005 Revised National Curriculum Statement. Grades 7-9 (Schools) Senior Phase. Pretoria: Department of Education.

Fraenkel, J., N. Wallen and H. Hyun. 2012. How to design and evaluate research in education $\left(8^{\text {th }}\right.$ ed). New York: McGraw Hill.

Freyberg, P. and R. Osborne. 1985. Assumptions about teaching and learning. In R. Osborne \& P. Freyberg, Learning in science. The implications of children's science. Auckland: Heinemann.

Futuyma, D. 2009. Evolution ( $2^{\text {nd }}$ ed.). Sunderland, Massachusetts, USA: Sinauer Associations, Inc. Publishers.

Gawande, A. 2011. The checklist manifesto: How to get things right. London: Profile Books.

Goodlad, J.,M. Klein and K. Tye. 1979. The domains of curriculum and their study. In J. Goodlad and Associates, Curriculum inquiry: The study of curriculum practice, 43-77. New York: McGraw-Hill Book Company.

Gregory, T. 2009. Understanding natural selection: Essential concepts and common misconceptions. Evolution: Education and Outreach 2(2):156-175.

Grey, J. 1999. Textbook quality in question. The Teacher, September 1999:4.

Helldén, G. and J. Solomon. 2004. The persistence of personal and social themes in context: Long- and short-term studies of students' scientific ideas. Science Education 88(6):885-900.

Hutchinson, T. and E. Torres. 1994. The textbook as agent of change. ELT Journal 48(4):315-328.

Jiménez Aleixandre, M. 1994. Teaching evolution and natural selection: A look at textbooks and teachers. Journal of Research in Science Teaching 31(5):519-535.

Kagan, T. and M. Sanders. 2013. Use of confidence scales in analysing unscientific ideas about evolution among religious Jewish students. African Journal of Research in Mathematics, Science and Technology Education 17(1):38-49.

Krippendorff, K. 2013. Content analysis: An introduction to its methodology ( $3^{\text {rd }}$ ed.) Thousand Oaks, California: Sage.

Lawrence, S. 2015. A longitudinal study of Life Sciences students' unscientific ideas about evolution. Unpublished MSc research report, University of the Witwatersrand, South Africa. 
Lever, J. 2002. Science, evolution and schooling in South Africa. In James, W. and Wilson, L. (Eds.), The architect and the scaffold: Evolution and education in South Africa, 10-44. Cape Town: Human Sciences Research Council.

Miles, M. and A. Huberman. 1994. An expanded sourcebook: Qualitative data analysis (2 ${ }^{\text {nd }}$ ed.). Thousand Oaks: Sage.

Moore, R., G. Mitchell, R. Bally, M. Inglis, J. Day and D. Jacobs 2002. Undergraduates' understanding of evolution: Ascription of agency as a problem for student learning. Journal of Biological Education 36(2):65-71.

Molefe, L. 2013. The pedagogical content knowledge of Life Sciences teachers teaching evolution for the first time. Unpublished M.Sc. research report, University of the Witwatersrand, Johannesburg, South Africa.

Mpeta, M. 2013. The influence of the beliefs of teachers and learners on the teaching and learning of evolution. Unpublished Ph.D. thesis, University of Pretoria, South Africa.

National Academy of Sciences. 2008. Science, evolution, and creationism. National Academy of Sciences Institutes of Medicine. Washington, DC: National Academies Press.

Naudé, F. 2013. The lived experiences of Christian teachers and learners of the teaching and learning of evolution in Life Sciences. Unpublished M.Ed. research report, University of Johannesburg, Johannesburg, South Africa.

Nehm, R., T. Poole, M. Lyford, S. Hoskins, L. Carruth, B. Ewers and P. Colberg. 2009. Does the segregation of evolution in biology textbooks and introductory courses reinforce students' mental models of biology and evolution? Evolution: Education and Outreach 2(3):527-532.

Nehm, R., M. Rector and M. Ha. 2010. 'Force-talk' in evolutionary explanation: Metaphors and misconceptions. Evolution: Education and Outreach 3(4):605-613.

Ngxola, N. and M. Sanders. 2009. Teachers' content knowledge for teaching evolution for the first time: Perceptions and reality. Vol 2 of the proceedings of the $17^{\text {th }}$ Annual Conference of the Southern African Association for Research in Mathematics, Science, and Technology Education, 19-22 January, Rhodes University, Grahamstown.

Ottevanger, W. 2001. Teacher support materials as a catalyst for science curriculum implementation Namibia. Doctoral dissertation, University of Twente, Enschede.

Pillay, C. 2011. The difficulties faced by some teachers with strong religious beliefs when they teach evolution. Unpublished MEd research report. University of the Witwatersrand, Johannesburg.

Prinou, L., L. Halkia and C. Skordoulis. 2008. What conceptions do Greek school students form about biological evolution? Evolution: Education and Outreach 1(3):312-317.

Reddy, L and M.Sanders. 2014. The potential influence of Life Sciences examinations on misconceptions about evolution. Proceedings of the $22^{\text {nd }}$ Annual Conference of the Southern African Association for Research in Mathematics, Science, and Technology Education, 1316 January. Nelson Mandela Metropolitan University, Port Elizabeth.

Rees, P. 2007. The evolution of textbook misconceptions about Darwin. Journal of Biological Education 41(2):53-55.

Sanders, M. 2010. Teaching evolution in a multi-cultural society: Teachers' concerns and management strategies for coping with conflict. Proceedings of the $14^{\text {th }}$ International Organization for Science and Technology Education symposium. Socio-cultural and Human Values in Science and Technology Education, 13-18 June 2010, Bled, Slovenia.. 
Sanders, M. 2014. Teleological and anthropomorphic thinking, and misconceptions about biological adaptations in Natural Sciences textbooks. Proceedings of the $22^{\text {nd }}$ Annual Conference of the Southern African Association for Research in Mathematics, Science, and Technology Education, 13-16 January, Nelson Mandela Metropolitan University, Port Elizabeth.

Sanders, M. and N. Ngxola. 2009. Identifying teachers' concerns about teaching evolution. Journal of Biological Education 43(3):121-128.

Schroder, D. 2012. An investigation into the attitudes of teachers and learners towards evolution, the conceptual changes that occur when learners are taught evolution, and the factors that influence these conceptual changes. Unpublished M.Ed. Research Report, University of KwaZulu-Natal, Pietermaritzburg, South Africa.

Stears, M. 2006. The FET curriculum and the teaching of evolution - what are the challenges facing teachers? Proceedings of the 3rd biennial conference of the South African Association for Science and Technology Educators, 4-6 July, University of Kwazulu-Natal, South Africa pp. $177-182$.

Stears, M. 2012. Exploring biology education students' responses to a course in evolution at a South African university: Implications for their roles as future teachers. Journal of Biological Education 46(1):12-19.

Stern, L. 2004. Effective assessment: Probing students' understanding of natural selection. Journal of Biological Education 39(1):12-17.

Thompson, J. 2008. Use the word evolution. Evolution: Education and Outreach 1(1):42-43.

Tshuma, T. and M. Sanders. 2015. Textbooks as a possible influence on unscientific ideas about evolution. Journal of Biological Education, 49(4):354-369. http://dx.doi.org/10.1080/0021 9266.2014.967274.

Van den Akker, J. 2004. Curriculum concepts and challenges. In K. O-saki, K. Hosea, \& W. Ottevanger (Eds.), Reforming science and mathematics education in sub-Saharan Africa. University of Dar es Salaam: TEAMS Project.

Verspoor, A. and K. Wu. 1990. Textbooks and educational development. Washington DC: Educational and Employment Division, Population and Human Resources Department, The World Bank.

Weber, R. 1990. Basic content analysis (2nd ed.). Newbury Park, CA: Sage Publications.

Woodward, A. and D. Elliott. 1987. Evolution and creationism in high school textbooks. The American Biology Teacher 49(3):164-170.

Yalvac, G. 2011. Barriers in the teaching and learning of evolutionary biology amongst Muslim teachers and learners in South African Muslim schools. Unpublished M.Ed. dissertation, University of Johannesburg, South Africa.

Yates, T. and E. Marek. 2014. Teachers teaching misconceptions: A study of factors contributing to high school biology students' acquisition of biological evolution-related misconceptions. Evolution: Education and Outreach 7 (paper 7). Retrieved from http://www.evolutionoutreach.com/content/7/1/7 (accessed March 2014). 